\title{
PREOPERATIVE RISK-OF-DEATH PREDICTION MODEL IN HEART SURGERY WITH DEEP HYPOTHERMIC CIRCULATORY ARREST IN THE NEONATE
}

Robert R. Clancy, MD

Susan A. McGaurn, PharmD

Gil Wernovsky, MD

Thomas L. Spray, MD

William I. Norwood, MD, PhD

Marshall L. Jacobs, MD

John D. Murphy, MD,

J. William Gaynor, MD

James E. Goin, $\mathrm{PhD}$
Objective: Our goal was to generate a preoperative risk-of-death prediction model in selected neonates with congenital heart disease undergoing surgery with deep hypothermic circulatory arrest. Methods: We completed a single-center, prospective, randomized, double-blind, placebocontrolled neuroprotection trial in selected neonates with congenital heart disease requiring operations for which deep hypothermic circulatory arrest was used. An extensive database was generated that included preoperative, intraoperative, and postoperative variables. Variables (delivery, maternal, and infant related) were evaluated to produce a preoperative risk-of-death prediction model by means of logistic regression. An operative risk-of-death prediction model including duration of deep hypothermic circulatory arrest was also generated. Results: Between July 1992 and September 1997, 350 (74\%) of 473 eligible infants were enrolled with 318 undergoing deep hypothermic circulatory arrest. The mortality was 52 of $318(16.4 \%)$, unaffected by investigational drug. The resulting preoperative risk model contained 4 variables: (1) cardiac anatomy (two-ventricle vs single ventricle surgery, with/without arch obstruction), (2) 1-minute Apgar score ( $\leq 5$ vs $>5$ ), (3) presence of genetic syndrome, and (4) age at hospital admission for surgery ( $\leq 5$ or $>5$ days). Mortality for two-ventricle repair was 3.2\% (4/130). Mortality for single ventricle palliation was $25.5 \%$ (48/188) and was significantly influenced by Apgar score, genetic diagnosis, and admission age. The preoperative model had a prediction accuracy of $80 \%$. The operative risk model included duration of deep hypothermic circulatory arrest, which significantly $(P=.03)$ increased risk of death, with a prediction accuracy of $82 \%$. Conclusions: In this selected population, postoperative mortality risk is significantly affected by preoperative conditions. Identification of infants with varying mortality risks may affect family counseling, therapeutic intervention, and risk stratification for future study designs. (J Thorac Cardiovasc Surg 2000; 119:347-57)
From the Division of Neurology and the Cardiac Center of the Children's Hospital of Philadelphia, Philadelphia, Pa.

Current addresses: Divisions of Neurology (R.R.C., S.A.M.), Cardiothoracic Surgery (T.L.S., J.W.G.), and Cardiology (G.W.) of the Children's Hospital of Philadelphia; the Departments of Neurology (R.R.C., S.A.M.), Pediatrics (R.R.C., S.A.M., G.W.), and Surgery (T.L.S., J.W.G.) of the School of Medicine, University of Pennsylvania, Philadelphia, Pa; the DataMedix Corporation (J.E.G.), Media, Pa; the Nemours Cardiac Center, Alfred I. duPont Hospital for Children (W.I.N., J.D.M.), Wilmington, Del; Departments of Surgery and Pediatrics of the Jefferson Medical College, Thomas Jefferson University (W.I.N, J.D.M.), Philadelphia, Pa; Department of Surgery, St Christopher's Hospital for Children (M.L.J.), Philadelphia, Pa; and the Department of Cardiothoracic Surgery, MCP Hahneman School of Medicine (M.L.J.), Philadelphia, Pa.
Performed under contract with the National Institute of Neurological Disorders and Stroke, National Institutes of Health, NS-N012315. General Clinical Research Center nursing support was provided by NIH MO1-RR00240. Preoperative risk-of-death prediction-September 7, 1999.

Read at the Seventy-ninth Annual Meeting of The American Association for Thoracic Surgery, New Orleans, La, April 18-21, 1999.

Received for publication April 22, 1999; revisions requested July 7 , 1999; revisions received Sept 8, 1999; accepted for publication Oct 6, 1999.

Address for reprints: Robert Clancy, MD, Division of Neurology, The Children's Hospital of Philadelphia, 324 South 34th St, Philadelphia, PA 19104 (E-mail: Clancy@email.chop.edu).

Copyright @ 2000 by Mosby, Inc.

$0022-5223 / 2000 \$ 12.00+0 \quad \mathbf{1 2 / 6 / 1 0 3 4 6 1}$ 
$\mathrm{M}$ ore than one third of the 30,000 infants with congenital heart disease (CHD) born in the United States each year require surgical intervention in early infancy. ${ }^{1-3}$ The factors that influence immediate postoperative mortality are not completely understood. Many previous investigations have focused primarily on specific anatomic entities, the contributions of different surgical techniques, and the conduct of cardiac anesthesia. For many forms of CHD, heart surgery in the neonate necessitates both cardiopulmonary bypass (CPB) and deep hypothermic circulatory arrest (DHCA), which may independently confer time-dependent risks. ${ }^{4,5}$ The durations of CPB and DHCA themselves are dependent on the complexity of the defective anatomy, the medical status of the infants, and the skill of the surgeon. Consequently, the risk contributions attributed to CPB and DHCA are difficult to quantify.

The immediate modes of death after heart surgery in the neonate are generally known and include cardiac arrhythmias, shock, hemorrhage, and sepsis. However, a comprehensive method of quantifying preoperative mortality risks is not available. This study was conducted to determine whether preoperative characteristics could be identified that significantly affect mortality and to examine their relative contribution to death risk. The final purpose was to formulate a simple, broadly applicable risk-of-death prediction model across the spectrum of CHD.

\section{Methods}

Study population. Newborn infants admitted to the Cardiac Center of The Children's Hospital of Philadelphia from July 1992 to September 1997 for evaluation of CHD were screened for enrollment into a pharmacologic neuroprotection trial, the context in which the preoperative risk-ofdeath models were developed. The study was conducted as a single-center, stratified, randomized, blinded, placebo-controlled trial with study drug administered before, during, and after heart surgery with DHCA in the neonate.

Infants were enrolled in the trial and consequently were the target population of the risk model building if they satisfied the following criteria: congenital heart defect necessitating an operation in which DHCA was the chosen perfusion strategy; conceptional age* less than 45 weeks; absence of coincident lethal genetic disorders or severe multiple congenital abnormalities; and informed consent provided. Infants were excluded for the following reasons: neurologic unassessablity (from neuromuscular blockade), seizures or coma, elevated liver function tests, neutropenia, or if enrollment would have occurred less than 16 hours before the operation. The

*Age since conception is determined by adding legal age (time from birth) to estimated gestational age (eg, the conceptional age of a 3week-old, 37-week estimated gestational age infant is 40 weeks). study protocol was approved by the Committee for the Protection of Human Subjects.

William I. Norwood and Marshal L. Jacobs performed the operations during approximately the first half of the trial and Thomas L. Spray and J. William Gaynor performed the remainder. The surgical techniques were not standardized, although the Norwood procedure was performed for patients with hypoplastic left heart syndrome and single ventricle. Cardiac anesthesia was uniformly maintained during the trial, including alpha-stat acid-base management.

Data collection. A comprehensive database was generated, including clinical observations, laboratory values, imaging examinations, and neurodevelopmental test results. The database was temporally organized into three periods: (1) preoperative, (2) intraoperative, and (3) postoperative.

Preoperative observations. The general categories of preoperative information examined are provided in Table I. Categories were chosen because of their plausible relationship to survival and neurologic outcome and the reliable quality of the data. Preoperative observations included demographic data, maternal/fetal characteristics of gestation, and labor and delivery. Demographic data included mother's race, age, parity, socioeconomic status (Hollingshead index ${ }^{6}$ ), and the presence of maternal health conditions. Characteristics of the infants included gestational age, birth weight, sex, Apgar scores, age at admission to The Children's Hospital of Philadelphia, microcephaly (head circumference $\leq 2$ nd percentile for age), and the presence of a genetic or chromosomal syndrome. Diagnoses were based on a clear constellation of clinical findings to name a specific genetic syndrome (eg, Goldenhar) or abnormal chromosomal analysis (eg, 22q11 deletion). Other infants had definite dysmorphic features (eg, cleft palate) but not a specific, named genetic syndrome. The medical status of the heart, lungs, kidneys, liver, gastrointestinal tract, and bone marrow was also recorded.

The congenital heart defects of the infants were classified into 1 of 4 categories on the basis of preoperative echocardiograms: class I, two-ventricle heart without arch obstruction; class II, two-ventricle heart with arch obstruction; class III, single ventricle heart without arch obstruction, and class IV, single ventricle heart with arch obstruction.

Intraoperative and postoperative observations. Characteristics of the intraoperative period included the duration of surface cooling, lowest recorded nasopharyngeal temperature, duration of $\mathrm{CPB}$ cooling, DHCA time, duration of rewarming on $\mathrm{CPB}$, need for additional $\mathrm{CPB}$, and the use of modified ultrafiltration. Postoperative clinical end points for the neuroprotection trial were recorded during the intensive care unit stay, not to exceed 6 weeks after the operation. Observations included the occurrence of death, seizures, coma, and cardiac events.

Statistical considerations. The study population is characterized by the number of infants available for each variable, means and standard deviations for continuous data, and frequencies and proportions for categorical data. Exact $95 \%$ confidence intervals are presented for some proportions.

Model building was iterative, integrating clinical knowl- 
Table I. Preoperative variables examined

\begin{tabular}{|c|c|c|c|}
\hline $\begin{array}{l}\text { Demographics } \\
\qquad(n=3)\end{array}$ & $\begin{array}{l}\text { Newborn characteristics } \\
\qquad(n=13)\end{array}$ & $\begin{array}{l}\text { Maternal characteristics } \\
\qquad(n=11)\end{array}$ & $\begin{array}{l}\text { Early neonatal course } \\
\qquad(n=23)\end{array}$ \\
\hline $\begin{array}{l}\text { Race } \\
\text { Sex } \\
\text { Hollingshead score }\end{array}$ & $\begin{array}{l}\text { Birth weight } \\
\text { Gestational age } \\
\text { Size for dates } \\
\text { Delivery mode: } \\
\text { cesarean section vs vaginal } \\
\text { Apgar score at } 1 \mathrm{~min} \\
\text { Apgar score at } 5 \mathrm{~min} \\
\text { Delivery room resuscitation } \\
\text { Meconium passage/staining } \\
\text { Microcephaly } \\
\text { Genetic syndrome or } \\
\text { chromosomal abnormality } \\
\text { Family history of seizures/ } \\
\text { cerebral palsy } \\
\text { Oligohydramnios } \\
\text { Polyhydramnios }\end{array}$ & $\begin{array}{l}\text { Chronic circulatory } \\
\text { Anemia } \\
\text { Hypertension } \\
\text { Pre-eclampsia } \\
\text { Diabetes } \\
\text { Placental insufficiency } \\
\text { Infection } \\
\text { Urinary tract } \\
\text { Sexually transmitted diseases } \\
\text { Chorioamnionitis } \\
\text { Drug exposure } \\
\text { Alcohol } \\
\text { Tobacco } \\
\text { Illicit drugs }\end{array}$ & $\begin{array}{l}\text { Toxic-metabolic-infectious } \\
\text { Hypoglycemia and hyperglycemia } \\
\text { Hyponatremia and hypernatremia } \\
\text { Hypomagnesemia and hypermagnesemia } \\
\text { Infection (eg, sepsis, meningitis, pneumonia) } \\
\text { Necrotizing enterocolitis } \\
\text { Liver dysfunction } \\
\text { Renal dysfunction } \\
\text { Cardiorespiratory-circulatory } \\
\text { Age at hospital admission } \\
\text { Metabolic acidosis } \\
\text { Cardiac or respiratory arrest } \\
\text { Congestive heart failure } \\
\text { Anatomic class of CHD (class I, II, III, or IV) } \\
\text { Blood pressure instability/shock } \\
\text { Respiratory insufficiency } \\
\text { Pneumothorax } \\
\text { Assigned cardiothoracic surgeon (S1, S2, S3, S4) } \\
\text { Neurologic } \\
\text { Hydrocephalus } \\
\text { Brain infarction } \\
\text { Brain hemorrhage } \\
\text { Hypotonia } \\
\text { Lethargy } \\
\text { Hypothermia }\end{array}$ \\
\hline
\end{tabular}

edge and results of statistical analyses, with the intent of creating a broadly applicable parsimonious model. Because there were 52 deaths in the database it was determined a priori that a maximum of 5 prediction variables (10:1 ratio) would be allowed in the final preoperative risk prediction model. The logistic regression model $^{7}$ was used for selecting variables and characterizing their strength of associations with death, using the odds ratio and $95 \%$ confidence intervals. Logistic regression models the proportion of deaths and how these proportions are influenced by predictor variables. Mean values were substituted for candidate predictor variables with $5 \%$ or fewer missing values.

Categorical variables were formatted with the use of customary dummy variables structure. Dichotomous variables were coded as zero and one, with zero being the reference category. For exploration of initial models, ordinal and continuous (interval scaled) scaled data from the entire data set (Table I) were evaluated as collected or transformed by means of the natural logarithm for continuous data. Sums of binary variables representing maternal and infant infections, ischemic conditions, and cardiac, metabolic, and neurologic conditions (Table I) were evaluated for their association with death, as well as the individual binary variables. Stepwise logistic regression (entry $P$ values of $.25, P$ value to stay of .1) was used to facilitate and verify the final model selection of variables; however, statistical knowledge gained through separate analyses and clinical knowledge guided the selection
Table II. Patient disposition summary

\begin{tabular}{lrc}
\hline & $N$ & Percent \\
\hline Enrolled & 350 & 100.0 \\
$\quad$ Reason excluded & & \\
$\quad$ No operation & 8 & 2.3 \\
$\quad$ No DHCA & 24 & 6.9 \\
$\quad$ DHCA population & 123 & 90.9 \\
Not enrolled & & 100.0 \\
$\quad$ Reason not enrolled & 57 & \\
$\quad$ Consent denied & 62 & 46.3 \\
$\quad$ Immediate operation & 3 & 50.4 \\
$\quad$ Immediate death & 1 & 2.4 \\
Other & & 0.8 \\
\hline
\end{tabular}

process. Continuous variables that were strongly considered for model selection were also evaluated on the basis of quartiles. Strong statistical support and/or a clear clinical rationale for inclusion of variables into the final preoperative prediction model were required.

Model fit was determined by means of the Hosmer and Lemeshow $^{8}$ method, and the deviance method was used for dispersion correction. The area under the receiver operating characteristic (ROC) curve is a measure of the overall prediction accuracy of the logistic model and, with its associated standard error, ${ }^{9-11}$ was used to evaluate different models. The ROC curve is a graphic way of presenting separations 
Table III. Demographic and selected preoperative characteristics $(N=318)$

\begin{tabular}{|c|c|c|c|c|}
\hline & $N$ & Percent & & \\
\hline \multicolumn{5}{|l|}{ Sex } \\
\hline Male & 186 & 58.5 & & \\
\hline Female & 132 & 41.5 & & \\
\hline \multicolumn{5}{|l|}{ Ethnicity } \\
\hline White & 242 & 76.1 & & \\
\hline African American & 46 & 14.5 & & \\
\hline Hispanic & 15 & 4.7 & & \\
\hline Other & 15 & 4.7 & & \\
\hline Delivery room resuscitation & 138 & 43.4 & & \\
\hline Microcephaly & 27 & 8.5 & & \\
\hline Specific genetic syndrome & 28 & 8.8 & & \\
\hline \multirow[t]{2}{*}{ Dysmorphism (no syndrome) } & 56 & 17.6 & & \\
\hline & & Mean $\pm S D$ & Median & $Q_{1}, Q_{3}$ \\
\hline Gestational age (wk) & 318 & $38.5 \pm 2.2$ & 39.0 & 38,40 \\
\hline Birth weight $(\mathrm{kg})$ & 309 & $3.1 \pm 0.6$ & 3.2 & $2.8,3.6$ \\
\hline Admission age (d) & 318 & & 2.0 & 1,5 \\
\hline Apgar score at $1 \mathrm{~min}$ & 301 & $7.5 \pm 1.6$ & 8.0 & 7,8 \\
\hline Apgar score at $5 \mathrm{~min}$ & 301 & $8.5 \pm 1.1$ & 9.0 & 8,9 \\
\hline Hollingshead score & 311 & $37.7 \pm 17.3$ & 39.0 & 27,53 \\
\hline
\end{tabular}

$Q_{1}$, Lower quartile (25\%); $Q^{3}$, upper quartile $(75 \%)$.

Table IV. Distribution of genetic syndromes $(N=318)$

\begin{tabular}{lcc}
\hline Final diagnosis & $N$ & Percent \\
\hline CHARGE & 1 & 0.3 \\
Goldenhar & 3 & 0.9 \\
Turner & 2 & 0.6 \\
VACTERL & 4 & 1.3 \\
Velocardiofacial & 1 & 0.3 \\
22q11 deletion & 9 & 2.8 \\
Dicentric 22 & 1 & 0.3 \\
Trisomy 7 & 1 & 0.3 \\
Trisomy 21 & 5 & 1.6 \\
Trisomy 13 & 1 & 0.3 \\
Total & 28 & 8.8 \\
\hline
\end{tabular}

CHARGE, Coloboma, heart disease, atresia choanae, retarded growth and retarded development and/or central nervous system anomalies, genital hypoplasia, and ear anomalies and/or deafness; VACTERL, vertebral abnormalities, anal atresia, cardiac abnormalities, tracheoesophageal fistula and/or esophageal atresia, renal agenesis and dysplasia, and limb defects.

between two groups and is a plot of percent of deaths predicted to die versus percent of survivors predicted to die. This curve is generated by creating a frequency distribution of model-generated predicted probabilities and by using each of the observed predicted probabilities as a threshold for classification. For a given threshold value (predicted probability), all cases above the threshold are classified as a death, yielding the percent of those that died who were predicted to die and the percent of survivors predicted to die in survivors. Allowing the threshold to assume all observed predicted probabilities results in the ROC curve. The area under this curve is a measure of the probability that given a randomly selected case from the survivor group $(\mathrm{N}=266)$ and a randomly selected case from the death group $(\mathrm{N}=52)$, the case from the death group will be assigned a higher predicted probability of death. This measure is independent of the prior probability of death and is considered to represent accuracy of the prediction model. The area is provided on the basis of the fitted model using all of the data and using an approximate jackknife ${ }^{12}$ procedure, which provides predicted probabilities of death for each case, based on fitting the model with the remaining cases. The jackknife provides a conservative estimate of accuracy when using the same data set to create a model and estimate its accuracy. An exact logistic regression model was also fit to the preoperative variables.

The primary intent of the operative model was to evaluate the independent contribution of the duration of DHCA on death, adjusted for the variables in the preoperative model.

A risk stratification model was developed on the basis of the percent of deaths in each of the 18 (of a possible 24) unique combinations (profiles) of independent predictor variables represented in the preoperative logistic model. This model contains the information presented in the logistic model, but in a more clinically useful manner. The preoperative predictor variables will also be referred to as risk factors.

SAS (SAS Institute, Cary, NC) and LogXact (Cytel Software, Cambridge, Mass) software were used for all statistical analyses. All reported $P$ values are 2 -sided.

\section{Results}

Study population. A patient disposition summary is provided in Table II. A total of 350 infants were enrolled in the study from June 1992 until September 
Table V. Distribution of cardiac defects, anatomic classification, and death by defect

\begin{tabular}{|c|c|c|c|c|c|}
\hline \multirow[b]{2}{*}{ Type of defect } & \multirow[b]{2}{*}{ Anatomic class } & \multirow[b]{2}{*}{$N$} & \multirow[b]{2}{*}{ Percent } & \multicolumn{2}{|c|}{ Death } \\
\hline & & & & $N$ & Percent \\
\hline HLHS & IV & 131 & 41.2 & 35 & 26.7 \\
\hline Single ventricle & IV & 40 & 12.6 & 7 & 17.5 \\
\hline Heterotaxy & III and IV & 10 & 3.1 & 3 & 30.0 \\
\hline TGA/intact ventricular septum & I & 36 & 11.3 & 0 & 0 \\
\hline TGA/VSD & I & 13 & 4.1 & 0 & 0 \\
\hline TGA/VSD, CoAo & I & 1 & 0.3 & 0 & 0 \\
\hline ToF alone & I & 13 & 4.1 & 1 & 7.7 \\
\hline $\mathrm{ToF} / \mathrm{PA}$ & I & 11 & 3.5 & 0 & 0 \\
\hline ToF (other) & I & 5 & 1.6 & 0 & 0 \\
\hline VSD/CoAo & II & 12 & 3.8 & 1 & 8.3 \\
\hline VSD/interrupted aortic arch & II and III & 14 & 4.4 & 1 & 7.1 \\
\hline VSD (other) ${ }^{*}$ & I, II, and III & 9 & 2.8 & 1 & 11.1 \\
\hline Truncus arteriosus & $\mathrm{I}$ & 7 & 2.2 & 0 & 0 \\
\hline TAPVR & I & 6 & 1.9 & 0 & 0 \\
\hline Other & I, II, III, and IV & 10 & 3.1 & 3 & 30.0 \\
\hline Total & & 318 & & 52 & 16.4 \\
\hline
\end{tabular}

$H L H S$, Hypoplastic left heart syndrome; TGA, transposition of the great arteries; VSD, ventricular septal defect; CoAo, coarctation of the aorta; ToF, tetralogy of Fallot; $P A$, pulmonary atresia; TAPVR, total anomalous pulmonary venous return.

*Includes double-outlet right ventricle $(\mathrm{n}=3)$, double-outlet left ventricle $(\mathrm{n}=1)$, double-outlet right ventricle/subaortic stenosis/coarctation of the aorta $(\mathrm{n}=1)$, and ventricular septal defect $(n=4)$.

Table VI. Intraoperative characteristics

\begin{tabular}{lcc}
\hline & $N$ & Mean $\pm S D$ \\
\hline Surface cooling time (min) $^{*}$ & 318 & $68.1 \pm 20.5$ \\
CPB cooling time (min) & 318 & $11.8 \pm 7.4$ \\
DHCA time (min) & 318 & $53.7 \pm 15.2$ \\
First CPB rewarming time (min) & 318 & $27.3 \pm 13.6$ \\
& & Percent \\
Need for additional CPB & 45 & 14.2 \\
Modified ultrafiltration performed & 77 & 24.2
\end{tabular}

"Surface cooling time $=$ ambient room temperature, cooling blanket, ice bags applied to head.

Includes only the time the pump is running (excludes DHCA time).

Attempt to wean from CPB.

1997; however, 32 infants did not undergo surgery $(\mathrm{n}=$ $8)$ or DHCA $(n=24)$. Consequently, 318 infants were used to generate the risk model. There were 123 infants eligible for the study but not enrolled by reason of denied consent $(57 ; 46 \%)$, surgery before the 16-hour preoperative treatment window $(62 ; 50 \%)$, immediate death $(3 ; 2 \%)$, and other reason $(1 ; 0.8 \%)$. Mortality in eligible nonenrolled subjects was $25.2 \%$.

Demographics and preoperative characteristics are provided in Table III. The study population was predominantly full term, appropriate weight for gestational age, and white. Apgar scores were available in 301 subjects, with mean values of 7.5 at 1 minute and 8.5 at 5 minutes, with $43 \%$ receiving some form of delivery room resuscitation other than simple tactile stimulation
Table VII. Day of death after surgery

\begin{tabular}{lrc}
\hline Day of death & $N$ & Percent \\
\hline Day of surgery & 19 & 36.5 \\
Day after surgery & 9 & 17.3 \\
Day 3 through day 7 & 7 & 13.5 \\
Day 8 through day 14 & 13 & 25.0 \\
Day 15 through day 35 & 4 & 7.7 \\
Total & 52 & 100.0 \\
\hline
\end{tabular}

and blow-by oxygen. Admission occurred at an average age of 5.6 days. Two hundred ninety-six $(93.1 \%)$ of patients underwent surgery before 28 days after birth. Microcephaly occurred in 9\%, dysmorphism in $18 \%$, and definite genetic syndromes in 9\% (Tables III and IV). The distribution of cardiac defects, their associated mortality, and anatomic classes are shown in Table V.

Intraoperative characteristics of the study population are provided in Table VI. The mean CPB cooling time was 11.8 minutes, mean DHCA time was 53.7 minutes, and mean duration of CPB rewarming was 27.3 minutes. Additional periods of CPB were used in $14 \%$ and modified ultrafiltration was performed in $24 \%$.

Mortality. The overall mortality was $16.4 \%$ (52/318) and was unaffected by study year or investigational drug administration. Mortality was similar for classes III $(25 \% ; 2 / 8)$ and IV $(25.6 \% ; 46 / 180)$, which were therefore combined as a "single ventricle" group. Mortality in class I was $1 \%(1 / 102)$, in class II it was 
Table VIII. Distribution of four identified preoperative characteristics

\begin{tabular}{|c|c|c|c|c|}
\hline \multirow[b]{2}{*}{ Characteristics } & \multirow[b]{2}{*}{$N$} & \multirow[b]{2}{*}{$\%$} & \multicolumn{2}{|c|}{ Mortality } \\
\hline & & & $N$ & $\%$ \\
\hline \multicolumn{5}{|c|}{ Congenital heart disease classification } \\
\hline Class I & 102 & 32.1 & 1 & 1.0 \\
\hline Class II & 28 & 8.8 & 3 & 10.7 \\
\hline Class III & 8 & 2.5 & 2 & 25.0 \\
\hline Class IV & 180 & 56.6 & 46 & 25.6 \\
\hline \multicolumn{5}{|l|}{ Genetic syndrome } \\
\hline None & 234 & 73.6 & 30 & 12.8 \\
\hline Dysmorphism & 56 & 17.6 & 14 & 25.0 \\
\hline Genetic syndrome & 28 & 8.8 & 8 & 28.6 \\
\hline \multicolumn{5}{|c|}{ Apgar score at 1 minute } \\
\hline$\leq 5$ & 33 & 10.4 & 11 & 33.3 \\
\hline$>5$ & 285 & 89.6 & 41 & 14.4 \\
\hline \multicolumn{5}{|c|}{ Age at hospital admission (d) } \\
\hline$\leq 5$ & 239 & 75.2 & 35 & 14.6 \\
\hline$>5$ & 79 & 24.8 & 17 & 21.5 \\
\hline
\end{tabular}

Table IX. Risk of death based on the logistic regression model: Preoperative and operative

\begin{tabular}{|c|c|c|c|c|c|}
\hline \multirow[b]{2}{*}{ Model } & \multirow[b]{2}{*}{ Parameter estimate } & \multicolumn{2}{|c|}{ Odds ratio } & \multirow[b]{2}{*}{ Odds ratio $^{*}(95 \%$ CI $)$} & \multirow[b]{2}{*}{$\mathrm{P}$ value } \\
\hline & & Asymptotic & Exact & & \\
\hline \multicolumn{6}{|c|}{ Preoperative model (prediction accuracy $=80 \%$ ) } \\
\hline Intercept & -5.6549 & & & & \\
\hline \multicolumn{6}{|l|}{ Anatomy } \\
\hline Class II & 2.6896 & $14.7^{\ddagger}$ & $13.6^{\ddagger}$ & $1.6-134.0$ & .02 \\
\hline Class III + IV & 4.1054 & $60.7^{\ddagger}$ & $53.5^{\ddagger}$ & $8.5-433.5$ & .0001 \\
\hline Genetic syndrome & 1.8317 & $6.2^{\S}$ & $6.0^{\S}$ & $2.1-18.4$ & .001 \\
\hline Apgar score $\leq 5$ & 1.3821 & $4.0^{11}$ & $3.9^{\| \prime}$ & $1.7-9.5$ & .002 \\
\hline Age at admission $>5$ days & 0.6547 & $1.9^{\mathbb{T I}}$ & $1.9^{\mathbb{I I}}$ & $1.0-3.8$ & .06 \\
\hline \multicolumn{6}{|c|}{ Operative model (prediction accuracy = $82 \%$ ) } \\
\hline Intercept & -5.9021 & & & & \\
\hline \multicolumn{6}{|l|}{ Anatomy } \\
\hline Class II & 2.4580 & $11.7^{\ddagger}$ & & $1.4-94.7$ & .02 \\
\hline Class III + IV & 3.8075 & $45.0^{\ddagger}$ & & $7.1-286.9$ & .0001 \\
\hline Genetic syndrome & 1.7681 & $5.9^{\S}$ & & $2.1-16.3$ & .001 \\
\hline Apgar score $\leq 5$ & 1.2849 & $3.6^{11}$ & & $1.5-8.4$ & .003 \\
\hline Age at admission $>5$ days & 0.6958 & $2.0^{\mathrm{II}}$ & & $1.1-3.8$ & .03 \\
\hline \multicolumn{6}{|l|}{ DHCA time ${ }^{\dagger}$} \\
\hline 44 to $52 \mathrm{~min}$ & 0.3063 & $1.4^{\#}$ & & $0.5-3.9$ & .57 \\
\hline 53 to $62 \mathrm{~min}$ & 0.3894 & $1.5^{\#}$ & & $0.6-4.0$ & .44 \\
\hline$>62 \min$ & 1.0308 & $2.8^{\#}$ & & $1.1-7.1$ & .03 \\
\hline
\end{tabular}

"Wald confidence limits.

DHCA time = duration of deep hypothermic circulatory arrest.

Compared with class I anatomy.

${ }^{\S}$ Compared with no genetic syndrome.

"Compared with an Apgar score $>5$.

"Compared with age at admission $\leq 5$ days.

\#Compared with < 44 minutes.

$10.7 \%(3 / 28)$, and in classes III and IV it was $25.5 \%$ (48/188). Death occurred rapidly in the study population (Table VII). All deaths occurred within 30 days of the operation except for one that occurred on day 35 .
Logistic regression models. Four preoperative variables were significantly associated with death: anatomic classification, 1-minute Apgar score, genetic syndrome, and age at hospital admission. Table VIII 


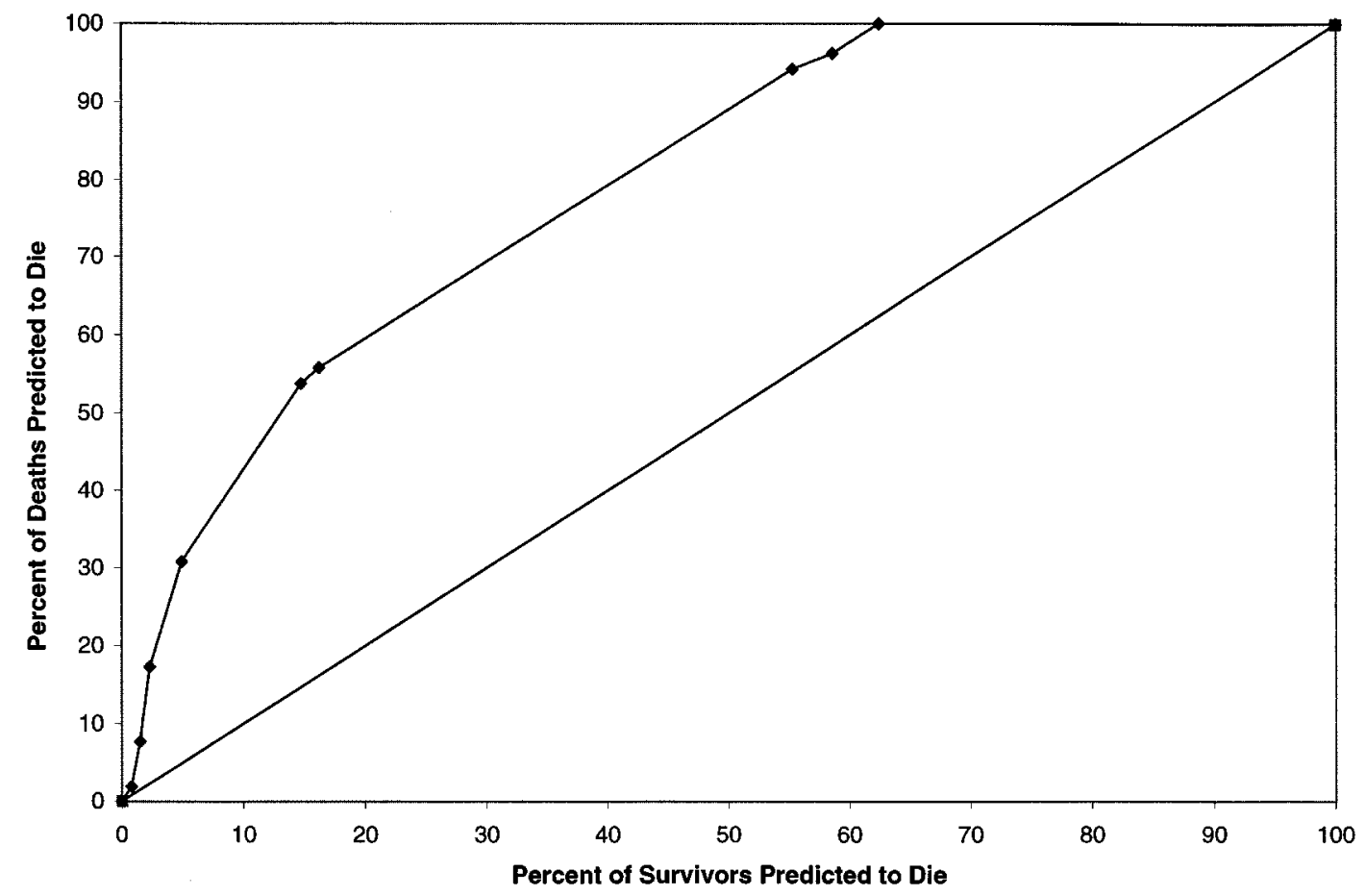

Fig 1. Preoperative risk-of-death logistic regression model ROC curve. Nonparametric area under ROC curve = $80 \%$; standard error of the area $=2.8 \%$.

provides the proportions of infants with these characteristics. The preoperative logistic model results (goodness of fit, $P=.9$ ) are presented in Table IX and the corresponding ROC curve is provided in Fig 1, which yields an accuracy of $80 \%$ (standard error of 2.8\%). However, the accuracy of the jackknife ROC curve was $70 \%$.

An operative risk-of-death model (goodness of fit, $P$ $=.9$ ) was also developed (Table IX) to evaluate the independent contribution of DHCA duration. The 4thquartile DHCA duration (>62 minutes) was associated with a significant increase in the odds of death (odds ratio $[\mathrm{OR}]=2.8 ; P=.03$ ). The accuracy (area under the ROC curve) increased to $82 \%$ (standard error of $2.7 \%$ ) by including DHCA duration.

Fig 2 provides a clinically relevant risk stratification tree with 6 terminal nodes (N1 to N6) into which all 318 study subjects are assigned on the basis of the 4 preoperative variables. The lowest percentage of death $(1 \% ; 1 / 102)$ was in node $\mathrm{N} 1$, characterizing infants with class I anatomy. Class II anatomy defines node N2 with a $10.7 \%(3 / 28)$ mortality. Combined classes III and IV had the highest mortality (25.5\%; 48/188). Within this group, a 1-minute Apgar score of 5 or less (node N3) was associated with a significantly increased mortality $(55.0 \% ; 11 / 20)$ compared with those with higher Apgar scores $(22.0 \%$; 37/168). In node N4 the mortality for single ventricle infants with Apgar scores more than 5 and a genetic syndrome $(55.6 \% ; 5 / 9)$ was significantly higher than for those without a genetic diagnosis $(20.1 \%$; 32/159). Terminal nodes N5 and N6 show the effects of "age at admission" on infants with no genetic syndrome and an Apgar score more than 5. "Age at admission more than 5 days" was associated with higher mortality $(31.6 \% ; 12 / 38)$ than that of patients admitted before 5 days $(16.5 \%$; 20/121). Finally, survival of single ventricle infants with favorable Apgar scores, genetics, and admission age was $83.5 \%$.

Another summary of the risk-of-death stratification is provided in Table $\mathrm{X}$, with mortality risk ranging from $1.0 \%$ to $55 \%$, depending on the CHD anatomic classification and the presence of risk factors.

\section{Discussion}

This study identified preoperative variables that were significantly associated with an increased risk of death after surgery. Death has always been intimately connected to the presence of CHD. Until recent decades, most severely affected infants with CHD died soon 


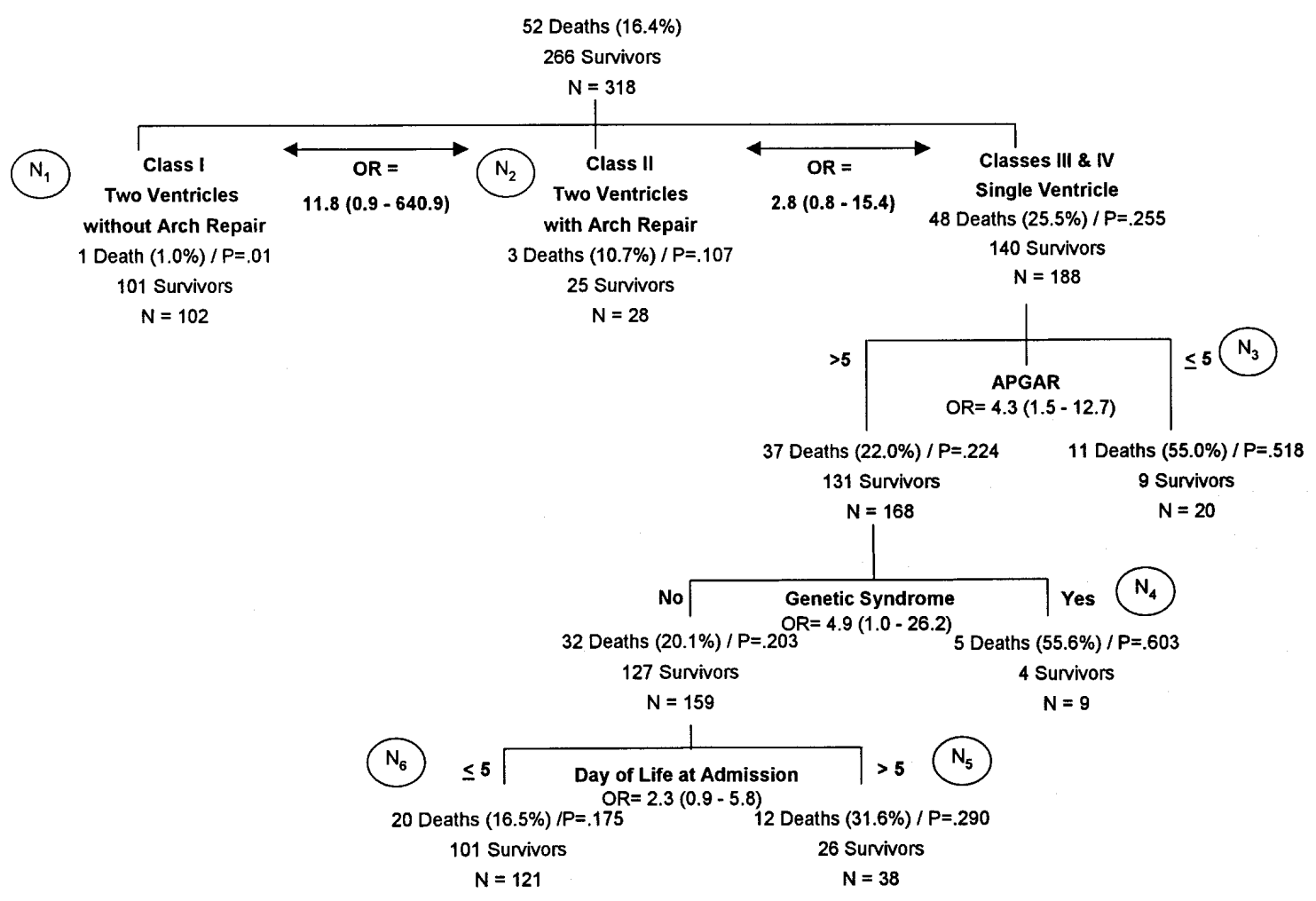

Fig 2. Preoperative risk of death stratification model with associated model predicted probabilities of death. $P$ represents the average of all node-predicted probabilities. OR, Odds ratio.

Table X. Preoperative risk of death stratification

\begin{tabular}{|c|c|c|c|c|}
\hline Class & $N$ & Deaths & Risk of death (\%) & $95 \% C I^{*}(\%)$ \\
\hline I. Dual ventricle without arch repair & 102 & 1 & 1.0 & $0.0-5.3$ \\
\hline II. Dual ventricle with arch repair & 28 & 3 & 10.7 & 2.3-28.2 \\
\hline III and IV. Single ventricle & 188 & 48 & 25.5 & $19.5-32.4$ \\
\hline 3a. No risk factors ${ }^{\dagger}$ & 121 & 20 & 16.5 & $10.4-24.4$ \\
\hline 3b. Greater than 5-day admission (only) & 38 & 12 & 31.6 & $17.5-48.7$ \\
\hline 3c. Genetic syndrome or low Apgar score & 29 & 16 & 55.2 & $35.7-73.6$ \\
\hline 3d. Any risk factor ${ }^{\dagger}$ & 67 & 28 & 41.8 & $29.9-54.5$ \\
\hline
\end{tabular}

${ }^{*}$ Exact binomial

${ }^{\dagger}$ Risk factors are genetic syndrome, Apgar score $<5$, and age at admission $>5$ days.

after birth or survived tenuously with chronic cyanosis, congestive heart failure, failure to thrive, and psychomotor delay. With the development of the technology used in cardiothoracic surgery, much attention has been focused on innovative surgical techniques and refining neonatal $\mathrm{CPB}$, DHCA, and modified ultrafiltration. The immediate modes of postoperative death are known and include myocardial failure, shock, hemorrhage, arrhythmias, systemic/pulmonary circulatory mismatch, and coronary artery insufficiency. However, knowing the circumstances surrounding death does not allow preoperative risk stratification. The purpose of this investigation was to attempt to identify preoperative variables that may be associated with immediate postoperative death. Estimating the strength of these associations and creating a risk stratification model were additional objectives. These goals were chosen since relatively few studies have examined the preexisting condition of infants before cardiac surgery, ${ }^{13-20}$ and none has produced a risk-of-death prediction 
model. Limperopoulos and associates ${ }^{13}$ reported the presence of microcephaly (occipitofrontal circumference $<3$ rd percentile) in $35.7 \%$ of 56 neonates before heart surgery and clinical neurologic abnormalities (eg, poor suck or low tone) in 28 of 50 (56\%) infants examined. In the study by Newburger and colleagues, ${ }^{17}$ preoperative examinations showed definite clinical neurologic abnormalities in 55 of 152 (36.2\%) infants before the operation. In the present study, infants frequently had low 1-minute Apgar scores, delivery room resuscitation, genetic syndromes, dysmorphic features, and microcephaly. Consequently, it is reasonable to seek clues regarding postoperative mortality among preoperative characteristics.

The mortality in this study (Table V) is comparable with that of other published series, ranging from $26 \%$ for single ventricle lesions, including hypoplastic left heart syndrome, to $3.2 \%$ for all other forms of complex neonatal heart disease. ${ }^{17,21,22}$ The proportion of deaths in the eligible, nonenrolled patients $(25.2 \%)$ was significantly $(P=.01)$ higher than that of enrolled infants $(16.4 \%)$. This was attributed mostly to the urgent need for surgery and immediate death in over half of the nonenrolled infants (Table II).

Not surprisingly, cardiac anatomy was a powerful preoperative predictor of mortality. There are specific anatomic variants within diagnostic groups that increase mortality risk. Examples are hypoplastic left heart syndrome with intact atrial septum or transposition of the great arteries with intramural coronary arteries. This speculative risk model uses a broad anatomic and physiologic classification scheme that was simple and easy to apply to individuals or classes of infants with CHD.

The presence of a specific named genetic syndrome was the second most potent modulator of risk of death. Abnormalities of chromosome 22, reported with about $5 \%$ of $\mathrm{CHD},{ }^{23}$ occurred in $3.5 \%$ (11/318) of study subjects. "Dysmorphism," present in $18 \%$ of other study infants, was also associated with a trend to increased risk of death $(\mathrm{OR}=1.963 ; P=.11)$. This suggests that increased mortality risk is not confined to a single genetic condition but is associated with any dysmorphic or genetic condition. This agrees with Bove's observation $^{24}$ that mortality in patients with hypoplastic left heart syndrome was significantly increased by noncardiac congenital conditions.

Apgar scores can be lowered by asphyxia, sepsis, shock, CHD, medications, and neurologic disorders. Depressed 5-minute Apgar scores traditionally correlate with morbidity such as cerebral palsy. ${ }^{25-27}$ In this study, low 1-minute Apgar scores were present in 10\% of the population and were associated with increased mortality, perhaps indicating that the CHD prevented a smooth circulatory transition from intrauterine life or that the CHD had already introduced a neurologic disorder.

Older age at admission was associated with a higher risk of death $(\mathrm{OR}=1.9 ; P=.06$ in the preoperative model; $\mathrm{OR}=2.0 ; P=.03$ in the operative model). The influence of age at admission on mortality was independent of prostaglandin administration and other preoperative characteristics. The mechanism by which age at admission affects mortality risk is unknown.

This study has several important strengths. It is comprehensive in its scope of CHD, includes a wide range of anatomic lesions, and reflects the experience of four cardiothoracic surgeons over a 5-year period. It is intuitively appealing that cardiac anatomy, Apgar scores, and genetic syndromes could be associated with an increased risk of death. The relative joint contribution of each variable to mortality was quantified in terms of odds ratios and segments the population into subgroups of varying risks. This variation in risk is considerable. For example, survival of patients with single ventricle complex with favorable genetics, Apgar score, and ageat-admission status was $83.5 \%$ (Table X, 3a), compared with $44.8 \%$ (Table X, $3 c$ ) in high-risk patients. After adjustment for the predictive preoperative variables, the length of DHCA time was associated with mortality risk. Those infants requiring between 44 and 62 minutes of DHCA had an odds ratio of approximately 1.5, and those requiring more than 62 minutes had an odds ratio of 2.8, compared with infants needing less than 44 minutes of DHCA.

The study also has important limitations. The risk model reflects the population from which it was derived-a selected group of neonates who underwent heart surgery with DHCA after fulfilling specific inclusion criteria for the neuroprotection trial. Unknown patient selection biases may exist, and the distribution of CHD lesions in this group is heavily weighted to single ventricle complexes. Although internally consistent, the risk-of-death model is speculative, has not been validated on an independent population, and probably exaggerates its predictive abilities. With the use of the jackknife method of generating the predicted probability of death, the ROC curve was constructed to measure the potential over-optimism of the regression model, and the resulting prediction accuracy fell to $70 \%$. Finally, great care should be exercised when considering the application of this information to an individual infant with CHD. The 95\% confidence intervals show a substantial range of mortality risk values, espe- 
cially in single ventricle lesions (Table X). Such information could be useful for counseling families of neonates awaiting heart surgery and for accommodating risk factors in future therapeutic interventional trials in this patient population.

In conclusion, it is important to acknowledge that the preoperative condition of these infants had a profound effect on survival. Potent predictors of mortality already exist before the operation commences.

We are indebted to the following for their contributions: Deborah Hirtz, Susan Nicolson, James Steven, Donna Sylvester, James Peterson, Michelle McErlane, Gerald Exil, David Jobes, Thomas McErlane, Brian Palmer, James Datillo, Elizabeth Leahy, Heung Dong Kim, Barbara Sands, Carol Roberts, Monica Ashbridge, Maryanne Vivino, William DeCampli, Maryanne Dubois, Judi Galter, Elaine Geary, Mike Solominow, Linda Corcoran, Sharon Zirin, and Jane Fricko.

\section{REFERENCES}

1. Benson D. Changing profile of congenital heart disease. Pediatrics 1989;83:790-1.

2. Gillum RF. Epidemiology of congenital heart disease in the United States. Am Heart J 1994;127:919-27.

3. Ferry P. Neurologic sequelae of cardiac surgery in children. Am J Dis Child 1987;141:309-12.

4. Wells FC, Coghill S, Caplan HL, Lincoln C, Kirklin JW. Duration of circulatory arrest does influence the psychological development of children after cardiac operation in early life. J Thorac Cardiovasc Surg 1983;86:823-31.

5. McConnell JR, Fleming WH, Chu WK, et al. Magnetic resonance imaging of the brain in infants and children before and after cardiac surgery. Am J Dis Child 1990;144:374-8.

6. Hollingshead A. Four factor index of social status. New Haven [CT]: Department of Sociology, Yale University; 1975.

7. Hosmer DW, Lemeshow S. Applied logistic regression. New York: John Wiley; 1989. p. 82-134.

8. Hosmer DW, Lemeshow S. Applied logistic regression. New York: John Wiley; 1989. p. 135-73.

9. Bamber D. The area above the ordinal dominance graph and the area below the receiver operating characteristic graph. J Math Psychol 1975;12:387-95.

10. Hanley JA, McNeil BJ. The meaning and use of the area under a receiver operating characteristic (ROC) curve. Radiology 1982; 143:29-36.

11. Goin JE, Preston DF, Gallagher JH, Wegst AV. Comparison of five digital scintigraphic display modes: an ROC curve analysis of detection performance. Med Decis Making 1983;3:215-27.

12. SAS Institute Inc. SAS/STAT software: changes and enhancements through release 6.12. 1997. p. 461.

13. Limperopoulos C, Majnemer A, Shevell MI, Rosenblatt B, Rohlicek C, Tchervenkov C. Neurologic status of newborns with congenital heart defects before open heart surgery. Pediatrics 1999;103:402-8.

14. Miller G, Eggli KD, Contant C, Baylen BG, Myers JL. Postoperative neurologic complications after open heart surgery on young infants. Arch Pediatr Adolesc Med 1995;149:764-8.
15. Brunberg JA, Reilly EL, Doty DB. Central nervous system consequences in infants of cardiac surgery using deep hypothermia and circulatory arrest. Circulation 1974;49-50(Suppl):II60-6.

16. Aisenberg RB, Rosenthal A, Nadas AS, Wolff PH. Developmental delay in infants with congenital heart: correlation with hypoxemia and congestive heart failure. Pediatr Cardiol 1982;3: 133-7.

17. Newburger J, Jonas R, Wernovsky G, et al. A comparison of the perioperative neurologic effects of hypothermic circulatory arrest versus low-flow cardiopulmonary bypass in infant heart surgery. N Engl J Med 1993;329:1057-64.

18. Blackwood MJA, Haka-Ikse K, Steward DJ. Developmental outcome in children undergoing surgery with profound hypothermia. Anesthesiology 1986;65:437-40.

19. Majnemer A, Limperopoulos C, Shevell MI, Rosenblatt B, Rohlicek C, Tchervenkov C. Neurologic status prior to and following open heart surgery in newborns and infants. Circulation 1997;96(Suppl):I130.

20. Haneda K, Itoh T, Togo T, Ohmi M, Mohri H. Effects of cardiac surgery on intellectual function in infants and children. Cardiovasc Surg 1996;4:303-7.

21. Bartram U, Grunenfelder J, Van Praagh R. Causes of death after the modified Norwood procedure: a study of 122 postmortem cases. Ann Thorac Surg 1997;64:1795-802.

22. Kern JH, Hayes CJ, Michler RE, Gersony WM, Quaegebeur JM. Survival and risk factor analysis for the Norwood procedure for hypoplastic left heart syndrome. Am J Cardiol 1997;80:170-4.

23. Glover TW. CATCHing a break on 22. Nat Genet 1995;10:257-8.

24. Bove EL. Current status of staged reconstruction for hypoplastic left heart syndrome. Pediatr Cardiol 1998;19:308-15.

25. American College of Obstetrics and Gynecology, Committee on Obstetric Practice. Fetal distress and birth asphyxia. Washington [DC]: American College of Obstetrics and Gynecology; 1994. Committee opinion no. 137.

26. Nelson KB, Broman SH. Perinatal risk factors in children with serious motor and mental handicaps. Ann Neurol 1977;2:371-7.

27. Ellenberg JH, Nelson KB. Cluster of perinatal events identifying infants at high risk for death or disability. J Pediatr 1988;113: 546-52.

\section{Discussion}

Mr Marc R. de Leval (London, United Kingdom). I commend Dr Clancy and his colleagues for a well-conducted prospective study. The criteria of enrollment and the end points were well defined, and their very large data set was submitted to highly sophisticated statistical analysis. The demonstration that in a subset of high-risk patients, namely patients with a single ventricle, the strongest predictors of death were preoperative variables is extremely important. Traditionally, outcome analyses have concentrated on comparing intraoperative procedural variables, for example, DHCA, against hypothermic CPB, disregarding the preoperative variables. The objective of this study was to generate a prediction model of early deaths. The findings should help the authors to secure resources to extend similar studies to the late outcomes and to investigate the impact of those preoperative variables on late sequelae such as neurologic deficits and developmental delays. 
I have two questions. You indicated that 123 patients did not fulfill the criteria of enrollment, and the mortality in that subset of patients was significantly higher than that in the patients you have analyzed. Is it conceivable that by excluding those patients you lost the opportunity to identify other predictors of death?

Second, I understand that the operations were performed by two surgeons doing the first phase of the study and two others doing the second phase of the study and that the results were similar for all those surgeons. Without trying to diminish the role of the surgeons, I would like to ask whether you believe that the system or the institutions in which they work is more important than the individual surgeons in the production of excellence?

Dr Clancy. I thank you for those comments, Mr de Leval. The first question concerned the effect of the nonenrolled patients. The children in the nonenrolled group who died were not predominantly the single ventricle patients but rather those who had something critical about their anatomy that precluded their waiting for 16 hours. The mortality in nonenrolled patients who would have been in classes III and IV was the same as that in the enrolled patients in classes III and IV. The differences really came out in the more critical cases. From that point of view, what would have otherwise been a lower mortality in classes I or II could have been raised. However, with class I used as the reference point, those differences would not have violated the broad categorizations.
Part of the difficulty is whether to be "lumpers" or "splitters." I am sure that surgeons could give me, a neurologist, many examples of what should and should not be included in any one of these groups, but painting with a broad stroke kept this study fairly simple.

The second question concerns the importance of the surgeon versus the institution. We wanted to make a generalizable model, something that would not be institution-specific, predicting the results of a surgeon or a group of surgeons. However, the whole team really produces these results. For example, we have had the same cardiothoracic anesthesiologists at Children's Hospital for the whole series, and I think that is part of the reason why these numbers are as good as they are. Whether this factor can be applied to another institution, I do not know. It is always tempting to think that one's expertise is the reason for the good results, but much of what is going to happen to the patient is predetermined by the genetics and the condition of the child on admission to the hospital.

This is a speculative model derived from the data that we generated, so of course it fits our data. The question is whether it will hold up if we test it independently in another set of patients in another institution with different anesthesiologists and different surgeons. Testing this model on an independent data set of children is one of the jobs ahead of us. The reason it is consistent in our study is that it is derived from our own data.

\section{Authoritative}

The Journal of Thoracic and Cardiovascular Surgery is the most frequently cited thoracic/cardiovascular surgery journal in the Science Citation Index. An article in JTCVS is sited on average almost twice as often as those in the closest cardiothoracic journal. 